\title{
CAPOEIRA DIALOGIA: O CORPO E O JOGO DE SIGNIFICADOS
}

\section{ESP. LUCAS CONTADOR DOURADO DA SILVA}

Especialista em Educação Física (Universidade Estadual de Campinas)

Bacharel e Licenciado em Educação Física pela Faculdade Metropolitanas de Campinas. Membro do Grupo de Estudos de Educação Física no Desenvolvimento Infantil - GEEFIDI (Campinas - São Paulo - Brasil)

Email: lucaocontador@gmail.com

\section{MS. ALEXANDRE DONIZETE FERREIRA}

Professor efetivo e pesquisador do curso de Licenciatura em Dança da Universidade Federal de Goiás. Bacharel em Educação Física (Faculdade de Educação Física da Universidade Estadual de Campinas - Unicamp), Mestre Biologia Celular e Estrural, área de concentração em Anatomia Humana (Instituto de Biologia da Unicamp) e Doutorando em Artes da Cena (Instituto de Artes da Unicamp). Bailarino profissional sob registro 016150.

(Goiânia - Goiás - Brasil)

Email: alefef@gmail.com

\section{RESUMO}

Esse estudo tem por objetivo fazer discussões sobre o corpo e suas implicações na Capoeira, trazendo uma visão sobre ela para a área da Educação Física. A partir de uma pesquisa bibliográfica, busca-se relacionar a prática da Capoeira com a ideia do jogo como dialogia corporal, visto que não foi encontrado nenhum trabalho que tivesse uma análise do jogo da Capoeira enquanto dialogia. Para tanto, tenta-se abordar as relações dos significados afluentes do corpo social, relacionando-o com o que chamamos de corpo capoeira. O corpo capoeira será explicitado a partir da metáfora dos vários corpos, onde construímos a ideia da dialogia corporal como um processo. Buscamos identificar a construção dialógica desse corpo capoeira através de processos que permeiam o jogo dentro da roda. Entendemos que as considerações obtidas no final desse estudo apresentam um ponto de partida para a discussão da Capoeira e, principalmente, de seu jogo.

PALAVRAS-CHAVE: Capoeira; Educação Física; corpo; dialogia. 
Esse estudo tem por objetivo explorar alguns conceitos sobre linguagem e corpo, a fim de relacioná-los à prática da Capoeira' como expressão didática e pedagógica, dentro do processo de aprendizagem. Entendemos a Capoeira como dialogia corporal. Trata-se de um estudo de pesquisa bibliográfica que procura construir a ideia da Capoeira como dialogia corporal, associado à sua prática esportivizada. ${ }^{2}$ Para a revisão da bibliografia, fizemos uma procura utilizando como palavra chave Capoeira, na base de dados da biblioteca da Universidade Estadual de Campinas, bem como na Revista Brasileira de Ciências do Esporte, onde lemos os artigos encontrados e delineamos ao tema proposto. Nesse sentido, buscou-se contribuir com o entendimento do "corpo capoeira" ${ }^{3}$ e da sua relação com as diversas áreas da Educação Física.

Identificar a construção do corpo social como um dos vários elementos constitutivos do corpo capoeira perpassa pelo olhar teórico antropológico, no qual questões são levantadas, tais como: de que forma condutas são geradas para que se estabeleçam novos caminhos de tensão ${ }^{4}$ entre as regras sociais e a postura do capoeirista; quais são os imperativos dessas condutas; quais significados são "carregados" pelo corpo diante essas condutas? Como ponto de partida, aproximamos as contribuições de Mauss ( 1974 ) sobre "técnicas corporais" - aspectos da imitação

I. Utiliza-se do termo Capoeira com "C" maiúsculo para referenciá-la como patrimônio cultural brasileiro (BRASIL, 2008), que engloba todo o processo histórico cultural. E com "c" minúsculo, representa os jogadores de Capoeira.

2. A Capoeira não foge dos padrões sociais, é vinculada com a ideia do esporte principalmente a partir do século $X X$. Na verdade, atualmente, o esporte liga-se com praticamente todas as práticas de exercícios físicos. Esse consentimento é fortalecido quando se associa o esporte com a saúde, como se fosse a mesma coisa: faça esporte e terá saúde, resultado rápido e fácil. Dentro da Capoeira essa vinculação com o esporte aparece historicamente com seu reconhecimento social através de estudos como do "Guia do capoeira ou gymnastica brasileira" ( I 907) e Burlamaqui (1928) e na prática com Manoel dos Reis Machado e outros. Conhecido como Mestre Bimba, foi o primeiro a fazer tal atrelamento visando à construção de uma Capoeira mais digna, aquela aceita socialmente (esportivizada). Mestre Pastinha (Vicente Joaquim Ferreira Pastinha), que também se valeu desse processo de esportivização para consolidar a Capoeira Angola. E isso se estende até os dias atuais. Podemos pensar na Capoeira enquanto esporte, sendo uma faceta dentre várias outras.

3. Esse termo concerne o que chamamos de metáfora dos vários corpos. Essa metáfora identifica a construção do corpo capoeira (polissêmico) como a dialogia dos corpos. Essa dialogia é o que dá forma ao único corpo, o ser humano. A metáfora dos vários corpos consiste: o corpo sociocultural, o corpo físico, o corpo psíquico e o corpo ético. Um corpo mais que uma simples prática.

4. Essa tensão visualiza o problema não como um limite, mas como uma fronteira de possibilidades. Paulo Freire cita em sua obra Pedagogia da Esperança: um reencontro com pedagogia do oprimido esclarece outro termo com o mesmo princípio, chamando-o de "inédito-viável. 
prestigiosa que conduzem a uma especificidade do corpo em contextos históricos culturais distintos, incorporados tradicionalmente.

Quando falamos sobre Capoeira como dialogia corporal, presume-se um embasamento teórico a partir da dialogicidade da educação escrita por Freire (1 983). Para o autor, o diálogo verdadeiro é o meio pelo qual os seres humanos podem SER MAIS. O indivíduo consciente, que dialoga sobre sua realidade, consegue, pela opinião dos outros, visualizar sua realidade por ângulos diferentes, reforçando ou mudando suas opiniões, apropriando-se de formas variadas de olhar o mundo a fim de solucionar problemas, instigando a práxis e assim, novas possibilidades de transformações de sua própria realidade.

Dentro do que foi lido, (CAPOEIRA, 200 I , 2006; FALCÃO, 2006; ARAÚJO, 2004) não encontramos nada parecido ao tema do trabalho, apesar de contribuições sobre o entendimento da Capoeira no geral. Foram encontradas obras como do autor Silva (2008) e artigo de Santos (2009), que vinculam o termo diálogo corporal, Capoeira e linguagem. Esse trabalho se diferencia, ao propor conjugar a formação de uma dialogia corporal, que é diferente do diálogo. O termo dialogia presume o entendimento de que o corpo, no jogo da Capoeira, pergunta por uma via de ida que é linear, porque a intenção dela é única, quer presenciar uma resposta, entretanto, essa pode se dar por diversos vieses, percorrendo um caminho não mais linear, mas estabelecendo um outro paradigma inesperado, o espiral. Portanto, um processo dialógico se dá, necessariamente, de forma multifatorial e processual. Outro ponto importante é que a dialogia presume a reverberação dos significados corporais dos seres humanos, por ser um processo social e multifatorial de interação do próprio corpo com o dos outros. Compreende, assim, a construção do corpo capoeira, que configura a interação do indivíduo com a forma específica da Capoeira em lidar com o corpo. A Capoeira permite que o indivíduo utilize de seu corpo e que estabeleça relações com as outras práticas, que também o ressignificam, de tal modo que tensiona um e vários corpos ao mesmo tempo, porque a cada atividade ele é representado diferentemente, o que numa dinâmica radical possibilita várias leituras. Forma-se a corporeidade ${ }^{5}$ do indivíduo, que passa ser reformulada pelas experiências corporais vividas em conjunto com as relações da roda de Capoeira, que é causadora de tensões, criadora de problemas a serem superados, que urge hibridismos: o corpo ressignificado, re-pensado e criticizado.

Até agora abordamos sobre os caminhos pelos quais o trabalho se propõe discutir, visto que ele se justifica justamente numa elaboração de entender a Capoeira

5. Sobre corporeidade, sugerimos ao leitor a seguinte obra de: SANTIN (2003). 
e, mais precisamente, o seu jogo em relação ao corpo, colocando ao leitor um conhecimento sobre essa manifestação cultural. Sabe-se que a Capoeira se forma justamente em seu ritual: a roda - e é esse ritual o responsável por sua constituição, que permite com que o jogo aconteça. $\bigcirc$ jogo presume relações dos corpos que jogam e por isso tem um direcionamento próprio. Tais colocações serão melhores abordadas posteriormente. Nessa perspectiva com finco educacional, torna-se um rico conhecimento para o profissional de Educação Física discutir criticamente a Capoeira, como conteúdo nos diversos âmbitos da área.

\section{O CORPO E SEUS SIGNOS CULTURAIS}

Podemos dizer que a Educação Física surge a partir da existência do próprio corpo, aonde vem se estabelecendo como área de conhecimento através da utilização do mesmo nas diversas esferas de conhecimento (biológico, cultural, social, psíquico). Sendo assim, podemos inferir que há uma apropriação de conceitos, mas não do corpo em si, uma vez que ela o estuda e busca colocar em prática esses estudos, tornando-se esse o ponto de partida para todo o restante do texto.

Dentro da área, tradicionalmente, esse corpo era visto apenas "como um conjunto de músculos e ossos e não expressão da cultura” (DAOLIO, 2007 p. 2). Após a predominância da influência biológica, a partir dos anos 80 , surgiram outras formas de discussão sobre o corpo, associadas às questões das ciências humanas, as quais ampliaram as discussões da área.

Com essa mudança estrutural ideológica, o estudo da cultura propiciou para a Educação Física, abrangência da visão do corpo como expressão, sendo essa a nossa noção de corpo. Deixando explícito que "todas as manifestações corporais humanas são geradas na dimensão cultural [...] expressando-se diversificadamente e com significados próprios no contexto de grupos culturais específicos" (DAOLIO, 2007, p. 2).

Um dos precursores desse estudo do corpo através da cultura foi Mauss ( 1974 p. 40), que identificou e nomeou "as maneiras pelas quais os homens, de sociedade a sociedade, de forma tradicional, sabem servir-se de seu corpo". O nome que deu para as formas desse "servir-se" de seu corpo foi de "técnicas corporais". Nessa obra, Mauss descreve algumas situações do "servir-se" de seu corpo, conseguindo esclarecer de forma abrangente essa relação do corpo com a cultura.

Sendo assim, essas técnicas são formadas a partir de uma imitação prestigiosa, onde tanto a criança, como o adulto, imita movimentos que foram bem sucedidos por pessoas que detém alguma autoridade ou confiança sobre ela (MAUSS, 1974). Uma de suas descrições foi feita a partir de uma observação em Nova York, no 
hospital, quando verificou uma similaridade do andar das suas enfermeiras com a lembrança do andar das jovens francesas, sua terra natal. Após refletir, identificou que esse andar característico da cultura americana foi disseminado pelos filmes americanos, através do cinema, para a cultura francesa.

A Capoeira se apresenta como uma técnica corporal que vem sendo passada de geração a geração de forma tradicional. E ainda, tal descrição relaciona-se com o próprio ensinamento da Capoeira, pois ela fora ensinada pela observação, sensação e imitação dos movimentos e da roda, basicamente os Mestres mais antigos utilizavam essa forma de ensinamento (ABIB, 2004).

Utilizando a observação de Mauss, permite-se perceber que as técnicas corporais vão além do espaço de algum momento restrito, passa na realidade a compor os lugares que esse corpo ocupa e se movimenta, já que ele é uma forma de expressão. Obviamente que algumas formas de se comportar são pertinentes apenas em momentos distintos, porém e com certeza, os significados do se movimentar permanecem juntos com a pessoa indissociavelmente.

Como vimos, a imitação se faz a partir de um prestígio. Ela carrega em si alguns significados culturais tradicionais hegemônicos, como exemplo, o que é uma postura adequada ou correta ao se sentar diante da mesa para comer, a forma como se deve apresentar-se a outra pessoa educadamente, entre outras condições que dão significados.

Todavia, a imitação nos aparece como uma questão preponderante na construção da corporeidade dos indivíduos. Dentro dessa imitação existem movimentos corporais envolvendo-nos tão fortemente que não podemos escapar deles. $\bigcirc$ andar ereto presume não só uma imitação de prestígio, mas uma condição característica da evolução humana. Porque prestígio significa um valor. Com esse andar, o ser humano passou a utilizar as mãos, e o valor da utilização delas passou a ser preservado, desde então, justamente por sua utilidade. A imitação conduz a um valor, imitar alguém é um ato de valores.

Geertz (1989) faz uma análise interessante sobre a piscadela, que pode nos ajudar. Segundo ele, a piscadela tanto pode representar o ato de paquerar uma pessoa, como o incômodo de um cisco nos olhos, ou então, um tique nervoso. Ou seja, um mesmo movimento corporal pode representar várias coisas diferentes, pois todos os movimentos estão inseridos em contextos que os fazem adquirir qualidades de gestos, portanto, imbuídos de significados.

Uma análise que tal descrição nos permite fazer é que o próprio jogo da Capoeira se faz por interpretações dos movimentos do outro, assim como na colocação feita acima. Se a interpretação do jogo for feita de forma equivocada, quando menos esperar, a rasteira aparece, mostrando a real intenção do movimento anterior: 
distrair o jogador. Se fosse possível que, momentos depois, os mesmos jogadores fizessem o jogo igualmente, quem levou a rasteira fará outra interpretação, com sentido diferente, partindo do mesmo significado.

Assim, os movimentos corporais trazem consigo significados como expressão da cultura, imaginando-a como uma "máquina de costurar" significados nos corpos (RODRIGUES, 1987). Tal fenômeno cria uma teia de especificidades corporais nos grupos, caracterizando gestos e ações como, por exemplo, no vôlei, com suas características próprias e, assim, também na Capoeira. Portanto, as peculiaridades de cada prática engendram significados ao corpo. Porém, quais significados são esses?

Tornando-se a próxima fase desse trabalho, tentaremos abordar esses significados a partir da metáfora dos "vários corpos". "Vários corpos" são um - ser humano - que dialeticamente estabelece uma relação de corpos no jogo da Capoeira e que reverbera fora desse, como na roda da vida social. ${ }^{6}$ Cada experiência na Capoeira enriquece a corporeidade do individuo que assimila significados particulares dela, assim surge o corpo capoeira.

\section{DOS VÁRIOS CORPOS AO CORPO CAPOEIRA}

corpo, diante da cultura, foi concebido por nós carregado de significados e valores, sendo esses construídos diante das experiências dos indivíduos. Cada criatividade ideológica pode ser representada como forma de expressão humana, assim, a Capoeira, o Futebol e outros, tem seu próprio modo de orientação da realidade, englobando seus valores e suas práticas. Todavia, a ideologia é formadora do discernimento das coisas, é o espaço não visível onde a consciência recorre ao julgar o mundo. Quando o indivíduo olha a realidade, toma consciência dela, seu pensamento volta-se para um ideal, acrescentando um modo individual de interpretar, pensar e agir (como fizemos no capítulo anterior ao abordarmos sobre o jogo da Capoeira). Favorece, assim, uma atitude fundamentada por um julgamento intrínseco de coerência do que enxerga. ${ }^{7}$ Uma cadeia ideológica consiste no aparato

6. Entendemos o corpo em sua magnitude, onde os valores apreendidos dentro da roda da Capoeira acabam por influenciar todas as aprendizagens futuras e os momentos da vida social do indivíduo.

7. Não estou falando sobre certas pessoas que tem algum tipo de distúrbio que distorce a visão da realidade, exemplo a anorexia: uma doença onde a pessoa se enxerga gorda, mas que na verdade está magra. Doença que muda a realidade, onde a pessoa enxerga o que quer e não aquilo que the é real. Outro exemplo, quando por vezes, a pessoa tem uma visão dificultada pela própria realidade, num estado de opressão, o indivíduo está tão mergulhado dentro da situação que não consegue enxergar por novos outros ângulos. Mas, mesmo quando isso acontece, a ideologia que é formada pelo viver diário, é a fonte de inspirações, superações na busca de transformações, pelas tomadas 
das ideias enquanto realidade do pensamento. É nela onde o indivíduo busca seus horizontes. Se conseguires olhar a realidade, também consegues interpretá-la. Essa interpretação passa por um ideal. A maneira de diferenciar o bom e o mau, o belo e o feio é, na verdade, feita por reflexões sobre a ideia de um ideal - naquilo que crê - também influenciado pelo estado emocional momentâneo.

Basicamente, quando olhamos para o jogo da Capoeira, visualizamos gestos motores peculiares que, de alguma maneira, movimentam suas condutas ideológicas e também sua corporeidade. Assim, toda roda de Capoeira é responsável por construir sua corporeidade, já que faz parte desse processo de valores que existem numa prática corporal. Essas condutas cheias de sentidos e significados interpelam suas regras, deixando claro para aqueles e aquelas que a conhecem, o discernimento de sua representatividade no mundo. Se os gestos fossem interpretados, assim como a escrita, encontraríamos algo parecido com o livro sobre a libertação dos escravos no Brasil. Mesmo não se expressando tal como as letras, a Capoeira se expressa pelos movimentos corporais, formando seu vocabulário gestual. Um corpo imbuído de valores e significados, um corpo idealogizado. Esse corpo idealogizado é o que chamaremos de "corpo capoeira".

No primeiro contato prático que o indivíduo tem com a Capoeira, seus gestos motores aprendidos em sua história de vida são utilizados e agrupam-se com os gestos motores peculiares do jogo. $\bigcirc$ indivíduo troca experiências motoras, ampliando-as. É uma permuta sem perdas, onde a corporeidade do indivíduo se completa com a corporeidade das práticas com que ele se envolve.

Entretanto, o indivíduo que apreende e aprende através dos movimentos, não só o faz nas atividades físicas, mas também na vida e, por isso, no entrelaçamento dos seguintes aspectos: sociocultural, físico, psíquico e ético. Esse entrelaçamento é o que chamarei de metáfora dos vários corpos, que consiste numa visão sintética, para utilizar o termo de Geertz (1989), de que o ser humano é composto pelas variáveis biológicas, psicológicas, social e cultural. Tal explicação se dá pela citação do mesmo autor, utilizando as palavras de Lévi-Strauss citado por Geertz, 1989, p. 45 da seguinte forma:

[...] a explicação científica não consiste, como fomos levados a imaginar, na redução do complexo ao simples. Ao contrário, ela consiste, diz ele (Strauss), na substituição de uma complexidade menos inteligível por outra mais inteligível.

de decisões. Pois, ao haver uma reflexão mínima, o indivíduo procura melhorar as suas condições de vida. A Capoeira surge assim, diante a opressão, da consciência dos subjugados por uma vida mais digna, demonstrando que mesmo na dificuldade há esperança, forma de enxergar a realidade diferentemente. 
A metáfora utilizada contextualiza as diferentes dimensões corporais e as trocas dos valores que estão nesse corpo entre os aspectos supracitados. Como se ela dissesse "Procure a complexidade e a ordene-a" (GEERTZ, 1989, p. 45). Essa metáfora serviu de base para a construção de uma lógica de interpretação dos significados expressos pelo corpo na Capoeira:

- Corpo sociocultural: Esse corpo é representado pela dialética do indivíduo com suas influências socioculturais. Quando o indivíduo nasce, ele toma contato com o mundo. A realidade dele (cultura), além de moldar seus movimentos corporais, constrói sua ideologia diante das relações sociais, que o transforma, estrutura e dá significados. A Capoeira, enquanto uma prática pela qual o indivíduo toma contato, faz com que os sentidos e significados sejam permutados da prática com o indivíduo e vice-versa, pela própria estrutura ideológica dessa prática e do mesmo;

- Corpo orgânico (físico): Esse corpo é representado pela dialética do indivíduo com suas necessidades biofisiológicas. Identificar que precisa tomar líquido interpela a relação com as suas necessidades e vontades de preservação. Escolher dentre a água e o refrigerante, por exemplo, demanda para o indivíduo fazer sua escolha. Contudo, a escolha será pautada no que a água e o refrigerante, diante sua vontade e o aspecto sociocultural, representa. Se o indivíduo decide que quer água, ele atribui não só os valores de necessidade, contudo, o que pensa sobre o líquido e o que quer no momento. Além dessa necessidade, podemos pensar na própria prática da Capoeira, que exige que o indivíduo esteja capacitado para fazer os movimentos. Assim, saber que precisa de um bom descanso, para no outro dia conseguir jogar Capoeira, também é a relação do indivíduo com esse aspecto do corpo humano;

- Corpo psíquico: Esse corpo é representado pela dialética do indivíduo em suas reflexões, no pensar sobre si. A partir da consciência sobre a realidade, o indivíduo faz reflexões sobre o mundo e toma suas decisões. Como o ser humano é o corpo, pensar em si é pensar no corpo e suas influências sofridas pelas questões socioculturais e de necessidades físicas. Na prática da Capoeira, pensar em si é precisamente pensar no outro, visto que eles se movimentam em conjunto, se há a impossibilidade do outro se movimentar o jogo é anulado, isso significa que pensar em si é pensar no outro, 
para preservação do jogo, há o respeito. A própria noção do jogo leva-nos a entender a próxima dimensão;

- Corpo Ético: Esse corpo é a conjuntura dos corpos supracitados: sociocultural, físico e psíquico, que são responsáveis por construir o valor do corpo para o próprio indivíduo, dentro de um pano de fundo que são os valores morais. Essas relações montam e moldam incessantemente uma polissemia corporal. "Ético" representa a preocupação de preservação dos seres humanos em sua amplitude, divergindo do individualismo. ${ }^{8}$ No jogo da Capoeira, esse corpo ético surge precisamente na exigência própria desse jogo. Ambos precisam jogar, estar bem fisicamente e psicologicamente, e em contato com o mesmo meio sociocultural. $\bigcirc$ lado de preservação que deve existir. Sem o outro não há jogo nem roda. Não há canto nem palmas ou coro. $\bigcirc$ que acontece muitas vezes, observando rodas, é quando o capoeira não vê a importância do outro para si e para o jogo, no máximo entende que deve ser superior ao outro, ocasionando um jogo de proibição, de opressão e até brigas.

A metáfora dos vários corpos se caracteriza como uma polissemia dos corpos. Vimos apenas uma breve caracterização deles. Identificamos tais dimensões corporais, pois os valores corporais apreendidos dentro da roda são influenciadores desses aspectos e vice-versa, e transcendem-se, influenciando todas as etapas de vida do indivíduo nos diferentes âmbitos que ele percorre. $\bigcirc$ indivíduo é o mesmo em todos os lugares por onde passa, carregado de seus valores diante da roda da vida social. ${ }^{9}$

[...] é possível observar, através de um olhar atento, sinais evidentes do conceito de sermos um corpo como forma de estar-no-mundo sensível e inteligentemente, donde a necessidade do início de um diálogo de aprendizagem com o corpo próprio e o alheio. (MOREIRA, 2004, p. 100).

É um corpo que não se fecha em si, ele se completa e se expressa intencionalmente. Determinando que os valores corporais apreendidos na roda da

8. Segundo Hall (2006), nessa era da pós-modernidade ou hiper-modernismo a individualidade está realçada, onde o diferente é a razão do entender e julgar do senso comum. Não escapamos do senso comum, ele está em nós.

9. Esse termo condiciona a ideia da roda da Capoeira com a vida social do indivíduo, como mostrado na figura. 
Capoeira são de suma importância para o indivíduo, pois são transmitidos. Já que os indivíduos dialogiciam corporalmente, como isso acontece? Que valores estão atribuídos à dialogia corporal dentro da Capoeira? E porque chamamos o jogo de capoeira como dialogia corporal? Essas perguntas serão respondidas no decorrer do texto, não de forma completa, mas como introdução a esse entendimento.

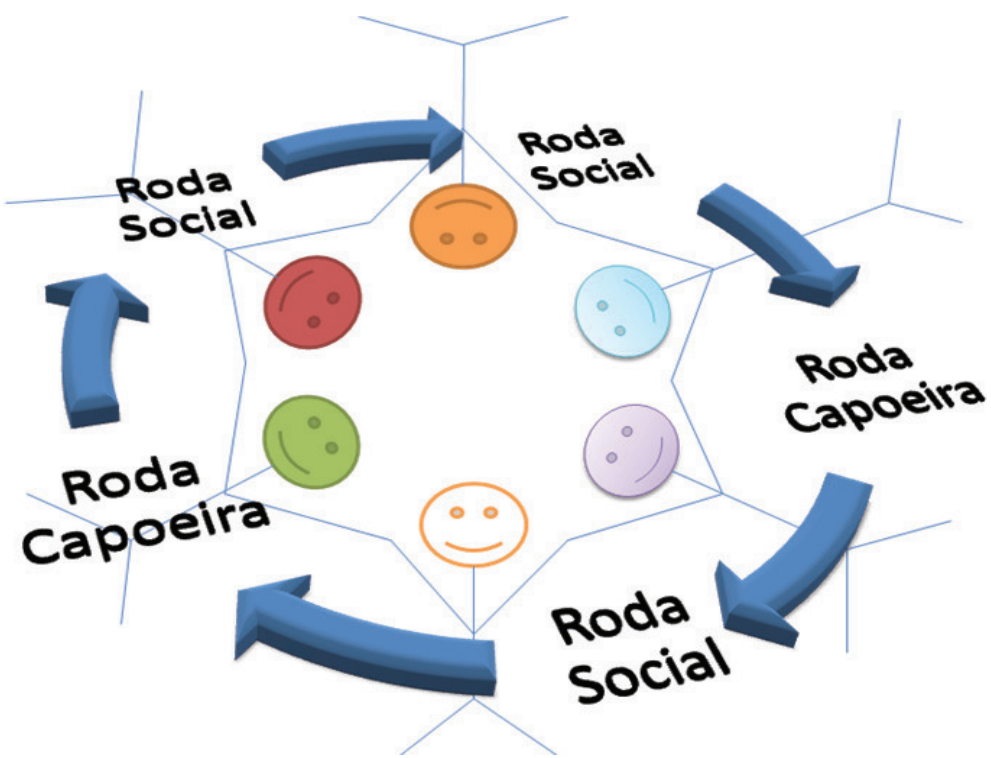

Figura I. A vida da roda social: o que se aprende na roda de Capoeira transita pelos caminhos em que o ser humano percorre, ainda quando, o valor atribuído dentro dessa prática fizer parte da realidade e daquilo que o indivíduo busca ser como ser humano.

\section{A CONSTRUÇÃO DO CORPO NO JOGO DA CAPOEIRA}

Foi por meio da capoeira que aprendi que o mais importante não é ser o melhor, é ser feliz, dentro do possível, durante as trajetórias de nossas atuações na vida, assim como a vida, a natureza da capoeira é cíclica. (SILVA, 2008, p. 13)

Quando os escravos foram trazidos da África ao Brasil dentro dos navios negreiros, os senhores tinham o costume de dividir os africanos pelas diferentes etnias, dificultando, assim, a comunicação e possíveis revoltas. Porém, com o convívio social, os escravos logo encontraram similaridades culturais que, mesmo diante das dificuldades causadas pela separação étnica e exploração, de algum modo, criou elos de identificação entre eles. (ABIB, 2004). Diante da dificuldade, esses elos 
representaram, através da ânsia pela liberdade, uma união necessária à vida, que criava condutas de expressões. Uma conduta de linguagem corporal. A favor da vida, essas condutas foram se alastrando pela cultura escrava, caracterizando-se em um corpo ideologizado, que tomava formas discretas contra um sistema opressor que tentava "calá-lo". A necessidade de uma expressão compartilhada pelos escravos impulsionou a criação ${ }^{10}$ de um dos pilares de sua identidade, " a Capoeira.

Situamo-nos novamente na ideia do corpo capoeira prevalecendo à questão da dialogia dos corpos, por isso constituído pelas experiências da vida. $\bigcirc$ corpo formado nessa ideia irriga os valores compreendidos na Capoeira, não só em seu espaço, mas na transcendência desse espaço, atingindo formas de expressão social da realidade. Tal ideia se remete à Educação Física, pois se sabe que a área utiliza dessa manifestação cultural para promover práticas corporais. Se pensarmos nessa discussão, por exemplo, na escola que prevê um direcionamento para tal conteúdo, fazendo emergir formas de atuar dentro da sala de aula, fazendo parte da realidade do aluno como algo significativo, promoverá mudanças nas atitudes do mesmo, havendo transformação social, ao passo que esse mesmo aluno se relacionará com várias outras pessoas que serão beneficiadas com tais atitudes e valores.

Dessa forma, chamarei de dialogia' ${ }^{2}$ o jogo que é feito na roda da Capoeira. Sabe-se que o jogo presume duas pessoas no centro da roda, tendo como objetivo envolver seu parceiro. Quando se joga não há a necessidade de embate, apenas de uma articulação entre seus jogadores, feita de forma espiral. É claro que o nível de articulação muda conforme o desenvolvimento e as capacidades dos indivíduos pelas necessidades que a prática exige, como também, a reciprocidade existente entre 0 jogo. Ou seja, quanto mais dispostos e convergentes estiverem os jogadores, mais eles articularão. Esse jogo se demonstra como uma troca de movimentos corporais.

Devemos saber que Capoeira só acontece quando se forma a roda: seu ritual representativo. Quando se treina ou se discute a Capoeira, no máximo o

10. A data da criação ou o surgimento da Capoeira é uma polêmica que "sobrevoa" as teorias que tentam explicá-la. Não existe nenhuma documentação, apenas alguns fatos que nos ajudam a formular tal ideia. Esse parágrafo foi escrito com base na tese de doutorado de Pedro Abib, para aqueles que queiram se aprofundar sobre a história da Capoeira.

I I. Sobre identidade cultural, ler obra de Hall (2006).

12. O termo dialogia é constituído a partir da ideia central de Paulo Freire, na sua obra Pedagogia do Oprimido, sobre eo diálogo. Segundo o autor, a existência humana nunca pode ser mudada, e sim, falada. O diálogo, quando verdadeiro, é um processo crítico e criativo que problematiza a realidade do indivíduo a buscar na práxis - ação/reflexão - transpor problemas geridos da vida. Sendo assim, o diálogo não pode ser compreendido isoladamente, mas principalmente com relação aos outros diálogo já vividos por alguém, por isso, pela formação dadialogia. Não cabe aqui discutir sobre toda proposta do autor, mas sim, tomar brevemente o conceito para aproximar o leitor do tema. Sugerimos a leitura da Obra citada. 
que acontece é um distanciamento/aproximação para repensar sobre a prática, transformando a aula em uma rota importante para desenvolver movimentos corporais mais expressivos e controlados. A roda é o espaço que determina o local do jogo, onde acontece a dialogia. A composição da roda no momento não nos é interessante, visto que cada grupo e capoeiristas defendem a formação dela com ideias diferentes. $\bigcirc$ intuito é não entrar nessa discussão.

A ideia de dialogia vem de um processo no jogo de Capoeira, onde um faz uma pergunta corporal e o outro, dentro de suas capacidades e vontades momentâneas, responde, insinuando uma nova pergunta, num processo dinâmico. Isso acontece porque os movimentos corporais, nesse deslocamento de pergunta e resposta, causam tensões entre os jogadores. Essas tensões podem denominar-se fronteiras, porém, não como um limite, mas como um campo de possibilidades, as quais emergem de um processo rizomático (DELEUZE; GUATTARI, 2000). Portanto, abre-se um leque de novas possibilidades ao se transpor a barreira corporal causada pela dinâmica pergunta-resposta do jogo.

Tornando-se imprescindível saber que, para essa dialogia acontecer, deve-se ter em mente que um jogo não pode ser de "A" para "B" ou de "A" sobre "B", mas de "A" com "B", mediados pelo mundo" (FREIRE, I 983 p. 98). Segundo o mesmo autor, a dialogia é o momento em que se consegue enxergar um problema por vários pontos de vistas, já que cada um opinará, de forma individual e diferente, como entende um problema a ser solucionado. Desse jeito, precisa-se ter humildade para aceitar o movimento corporal como ponto de vista do outro, para aceitar que essas trocas são importantes para causar uma mudança no próprio jeito de enxergar das coisas. A importância do outro nesse processo, do ser humano, valorizando-o.

Por isso que, nos momentos em que o indivíduo não transpassa obstáculos, vem a necessidade de "dialogiciar", ou seja, olhar um obstáculo por vários ângulos, para que então possamos decidir entre as várias maneiras de agir, o modo mais apropriado para o momento.

É claro que muitas das dialogias acabam não sendo tão harmoniosas, nos dando a sensação da conversa ficar um pouco falha. Por isso a importância das aulas para a aprendizagem, onde os gestos motores, cada vez mais, ficam encarnados no indivíduo, em conjunto com seus valores. É o que Silva (1993) chama de engrama motor. Segundo ele, o indivíduo, a partir da repetição, se acostuma com o movimento, havendo assim, um despêndio menor de energia na hora do movimento, tornando-o cada vez mais natural e bonito, consistindo uma criação, e não uma reprodução. São as técnicas, nesse caso, que ajudam a estruturar essa dialogia. Do mesmo modo que, quanto maior o vocabulário linguístico, maior são as possibilidades da construção das ideias para que haja uma conversa verbal mais rica. 
Durante a dialogia corporal que se estabelece na roda de Capoeira, os jogadores tensionam-se, abrindo novas possibilidades para o jogo acontecer. Cada possibilidade proporciona ao indivíduo novas tomadas de decisões, dando-lhe vários novos rumos. Esses rumos são causadores de novas expectativas, anseios, que impulsionam novas transformações. São rumos de idas e vindas, tensionados por todos os vieses desse ciclo de perguntas e respostas. Assim, cada vez que o indivíduo transpassa um obstáculo cheio de tensões, associadamente, lhe vem um sentimento de satisfação de seus atos, que o encoraja em desafios posteriores. Existem outros sentimentos envolvidos nesse contexto dialógico, como, por exemplo, o alívio, prazer, etc.

Como vimos, o corpo reverbera na vida social. Sua plenitude de sentimentos, irrigados pela roda, perpassam todos os âmbitos sociais, já que não há dissociação. Os sentimentos envolventes durante e pela dialogia corporal encorajam o indivíduo, não só a enfrentar obstáculos da roda de Capoeira, mas na totalidade de sua vida. Quando visualizamos um jogo de respeito, esse também é repassado diante a vida. $\bigcirc$ sentimento resguardado é totalmente do indivíduo, mas que, pela vontade de repartir diante dos outros, ele é ampliado indefinidamente para que todos possam sentir.

Dentro dessa ótica da reverberação de sentimentos, a Capoeira, rica de valores desde seu surgimento, ainda se faz presente na contemporaneidade. Em um mundo cheio de tecnologias, onde as mudanças são abruptas, encontramos na Capoeira a resistência de uma mudança não necessária, encontrada em sua história: luta encorajada em favor da vida humana. Uma atividade determinantemente corporal, que insinua coletividade e o pensar no outro, como pensar em si; rica pelos valores atribuídos em sua construção, no passado e no presente, para aqueles e aquelas que pensam no indivíduo coletivo. A capoeira dialogia corporal dentro da realidade que nos cerca, na Educação Física e no mundo.

Buscamos avançar numa análise do jogo da Capoeira, visto que ele é a expressão máxima do corpo, e que traz os fatores históricos. Assim, as palavras contidas aqui presumem olhar para a Capoeira e pensar sobre a prática dela, direcionado para o profissional de Educação Física em seus diversos âmbitos, sem descaracterizá-la como manifestação cultural.

Soares et al. (1992) foi o primeiro autor que nos atentou para que devemos entender a Capoeira enquanto linguagem e manifestação cultural dentro da Educação Física, pensando num processo educativo, e respeitando seu caráter histórico-cultural.

A Capoeira enquanto dialogia coloca um olhar sobre o ensinamento dessa arte brasileira, como caminho a ser utilizado pelos profissionais da nossa área. Vemos a Capoeira enquanto meio e fim educacional, significativo para o povo brasileiro pela sua história. Assim, até agora, buscamos entender o jogo dela e sua lógica. 
Abordamos sobre o jogo da Capoeira e a relação dos corpos nela envolvidos, porque sabemos bem que a área da Educação Física promove atividades corporais em diversos âmbitos, participando na formação de pessoas. Propusemos olhar para a Capoeira de forma crítica, trazendo contribuições para nossa área, particularmente sobre o seu jogo. Não queremos aqui dizer que a Capoeira é a única que possa ser trabalhada dessa maneira, apenas lançamos algumas ideias sobre uma forma de trabalhá-la.

\section{ÚLTIMAS PALAVRAS}

Diante das palavras com as quais, em sua conjuntura, formaram esse estudo, procuramos atingir nosso objetivo, entendendo o jogo da Capoeira como uma dialogia corporal. Vimos que a Capoeira, através de seu jogo, constrói significados corporais. Discutimos e explicamos como se dá à construção dos significados culturais vinculados ao corpo. Posteriormente, esse corpo foi dando cara ao que chamamos de corpo capoeira, sendo explicitado pela metáfora dos vários corpos. Levantamos algumas nuances do jogo da Capoeira como uma dialogia corporal, com seus aspectos de utilização dentro de uma perspectiva de olhar direcionada para a Educação Física.

Dialogia em si, de indivíduos que utilizam os movimentos corporais, transmitindo seus sentimentos e ideais, reverberando-os a cada tensão causada pela troca de gestos. Indivíduos atores, descobrindo sua importância a partir do outro, aprendendo do que são capazes a partir do que já sabem. Numa dialogia que desassocia, pelo menos em instante, ganhador e perdedor - pódio maçante da vida cotidiana. Que alívio!

Permitimos olhar o corpo através do jogo da Capoeira, para realçá-lo, sobretudo a propósito da Educação Física. De certa forma, mudamos nossos olhares sobre ele e sobre nós, seres humanos. Sendo importante considerar: se o corpo nos "fala", ${ }^{13}$ parece que ele tem mais a dizer do que a Educação Física tem conseguido "escutar". Como se ele gritasse: Veja-me! O que quero lhes dizer? Prestem muita atenção!

Por fim, entendemos que esse estudo não é algo completo, apenas um passo adiante no entendimento da Capoeira, não nos cabendo a análise do mesmo, mas, obviamente, como tarefa aos críticos e estudiosos do tema.

13. A fala é uma forma de expressão que é formada pelos signos. A dialogia corporal também. $\bigcirc$ que muda é o significado e o sentido de cada signo. 


\section{Capoeira dialogism: the body and the game of meaning}

ABSTRACT: This study aims to discuss the body and its implications in Capoeira, a vision of bringing it to the area of Physical Education. From a literature search, we try to relate the practice of Capoeira with the idea of the game as a corporal dialogue, since we could not find any study relating the game of Capoeira as a dialogue. To this end, attempts to discuss the relations between the meanings of the social body, relating it to what we call "capoeira body". Capoeira body is explained by the metaphor of "several bodies", where we build the idea of corporal dialogue as a process. We seek to identify the dialogical construction of capoeira body through processes that permeate the game inside the wheel of capoeira. We understand that the considerations obtained at the end of this study can be considered as a starting point for the discussion of Capoeira, and especially of its game.

KEYWORDS: Capoeira; physical education; body; dialogism.

\section{Capoeira dialogía: el cuerpo y el juego de sentidos}

RESUMEN: Este estudio tiene como objetivo a los debates sobre el cuerpo y sus implicaciones en la Capoeira, una visión de llevarla a la área de Educación Física. A partir de una búsqueda en la literatura, tratamos de relacionar la práctica de la Capoeira, con la idea del juego como un diálogo corporal, ya que no encontramos ningún estudio que tenía una opinión sobre el juego de la Capoeira como el diálogo. Con este fin, los intentos de abordar las relaciones de los afluentes significados del cuerpo social, relacionándolo con lo que llamamos cuerpo capoeira. El cuerpo se explicará capoeira de la metáfora de los distintos órganos, en el que construir la idea del diálogo corporal como un proceso. Tratamos de identificar la construcción dialógica del cuerpo capoeira a través de procesos que impregnan el juego dentro de la rueda. Entendemos que las consideraciones obtenidas al final de este estudio, tenemos como punto de partida para la discusión de la Capoeira, y especialmente de su juego.

PALABRAS CLAVE: Capoeira; educación física; cuerpo; dialogía.

\section{REFERÊNCIAS}

ABIB, P. R J. Capoeira angola: cultura popular e o jogo dos saberes na roda. 2004. I7I f. Tese (Doutorado em Educação Física) - Faculdade de Educação Física, Universidade Estadual de Campinas, Campinas, 2004.

ARAÚJO, P. C. Capoeira: novos estudos: abordagens sócio-antropológicas. Juiz de Fora: Irmãos Justiniano, 2004.

BURLAMAQUI, A. Gymnastica nacional (Capoeiragem): methodisada e regrada. Rio de Janeiro, 1928.

BRASIL. Ministério da Cultura. Instituto do Patrimônio Histórico e Artístico Nacional. Cadastro nacional da capoeira. 15 jul. 2008. Disponível em: < http://portal.iphan.gov.br/portal/ 
montarDetalheConteudo.do? $\mathrm{id}=13983 \&$ sigla $=$ Noticia\&retorno $=$ detalheNoticia.$>$ Acesso em: 23 set. 2011 .

CAPOEIRA, N. Capoeira: os fundamentos da malícia. 8. ed. Rio de Janeiro: Record, 200 I.

CAPOEIRA, N. Capoeira: pequeno manual do jogador. 8. ed. Rio de Janeiro: Record, 2006.

DAOLIO, J. Educação Física e o conceito de cultura. 2. ed. Campinas: Autores Associados, 2007.

DELEUZE, G.; GUATTARI, F. Mil platôs: capitalismo e esquizofrenia. 2. ed. São Paulo: Ed. 34, 2000.

FALCÃO, J. L. C. O jogo da capoeira em jogo. Revista Brasileira de Ciências do Esporte, Campinas, v. 27, n. 2, p. 59-74, jan. 2006. Disponível em: http://rbceonline.org.br/revista/ index.php/RBCE/article/dowload/88/95. Acesso em: I 5 nov. 2010.

FREIRE, P. Pedagogia da esperança: um reencontro com a pedagogia do oprimido. I3. ed. Rio de Janeiro: Paz e Terra, 1992.

FREIRE, P. Pedagogia do oprimido. 14. ed. Rio de Janeiro: Paz e Terra, 1983.

GEERTZ, C. A interpretação das culturas. Rio de Janeiro: Guanabara Koogan, 1989.

HALL, S. A identidade cultural na pós-modernidade. Rio de Janeiro: DP\&A, 2006.

GUIA do capoeira ou gymnastica brazileira. 2. ed. Rio de Janeiro: Livraria Nacional, 1907. (fac similar).

MAUSS, M. Sociologia e antropologia. São Paulo: EPU, 1974.

MOREIRA, W. W. Perspectivas da educação motora na escola. In: DE MARCO, A. (Org.). Pensando a educação motora. Campinas: Papirus, 2004.

RODRIGUES, J. C. O corpo liberado? In: STROZENBERG. I. (Org.). De corpo e alma. Rio de Janeiro: Comunicação Contemporânea, 1987. p. 90-100.

SANTIN, S. Educação Física: uma abordagem filosófica da corporeidade. 2. ed. ljuí: Ed. da Unijuí, 2003.

SANTOS, G. O. Alguns sentidos e significados da capoeira, da linguagem corporal, da Educação Física... Revista Brasileira de Ciências do Esporte, Campinas, v. 30, n. 2, p. I 23- I36. jan. 2009. Disponível em: http://rbceonline.org.br/revista/index.php/RBCE/aritcle/download/440/356. Acesso em: 18 set. 2009.

SILVA, E. L. Método de ensino integral da dança: um estudo do desenvolvimento dos exercícios técnicos centrado no aluno. 1993. 170 f. Tese (Doutorado) - Instituto de Artes, Universidade Estadual de Campinas, Campinas. 1993. 
SILVA, E. L. O corpo na capoeira: introdução ao estudo do corpo na capoeira. Campinas: Ed. da Unicamp, 2008.

SOARES, C. L. et. al. Metodologia do ensino da Educação Física. São Paulo: Cortez, 1992.

Recebido: 13 nov. 2010

Aprovado: 25 nov. 201।

Endereço para correspondência

Lucas Contador Dourado da Silva

Av: José Bonifácio, 124 Jardim Flamboyant.

Campinas/SP - CEP: |3.09|-|40 